\title{
Seeking Professional Help for Personal Problems: Black Americans' Use of Health and Mental Health Services
}

\author{
Harold W. Neighbors
}

\begin{abstract}
This article explored the use of health and mental health services for serious personal problems in a national sample of adult black Americans. The results indicated low usage of the mental health sector in response to problems. Only $9 \%$ of the respondents who sought professional help contacted a community mental health center, psychiatrist or psychologist. Mental health usage was low even among respondents who felt their problem brought them to the point of a nervous breakdown and among respondents who conceptualized their distress in "emotional" terms. The traditional health care sector (doctors, hospitals) and ministers were used more often by blacks in distress. When the use of professional help only is considered, there appeared to be a large pocket of unmet need in the black community. When the use of informal help is taken into consideration, however, the percentage of respondents who did not receive help was considerably lower. The implications of these findings for professional service delivery are discussed.
\end{abstract}

Many psychiatric epidemiologic studies of race differences in mental health status relied heavily on rates-under-treatment statistics to estimate psychiatric morbidity (Frumkin, 1954; Malzberg, 1953, 1959; Fried, 1975). This method was used to estimate mental health status primarily because of difficulties in operationally defining mental illness and due to the fact that the short symptom checklist approach to measurement had not yet been sufficiently developed. Treatment rate studies have been thoroughly criticized as being inadequate for estimating the distribution of psychiatric disorder in general populations (Fischer, 1969; Thomas \& Sillen, 1972; Cannon \& Locke, 1977; Kramer et al., 1973). The major criticisms against such studies concern the tremendous variability known to exist in illness behavior and help seeking in

Direct all communications to: Harold W. Neighbors; University of Michigan; Institute for Social Research; Room 5134; Ann Arbor, Michigan 48106. The preparation of this article was supported by a grant from the National Institute for Mental Health (Center for Minority Group Mental Health) and the Rockefeller Foundation. The author would like to thank Linda Chatters, James Jackson and two anonymous reviewers for their comments on earlier drafts of this paper. The author would also like to thank Beverly Williams for typing this manuscript. 
general (Gurin et al., 1960; Mechanic, 1983; Veroff, Kulka \& Douvan, 1981).

The problem with treatment rate studies is that they use statistics which describe demand-for-professional-help in an attempt to infer need-for-help. The two are not necessarily equivalent. Personal feelings of distress are not always defined as a "medical" or "health" problem, a definition which may increase the likelihood of seeking some type of professional help. Such feelings of distress are even less likely to be defined as a "psychiatric" or "mental health" problem, a definition which may increase the probability of utilizing a mental health resource for help. Finally, even when distress is defined as a health or mental health problem the subjectively felt need does not always translate into a demand for help, much less a demand for medical or mental health assistance.

Treatment rate studies raise more questions about the black help seeking process than they answer about black mental health status. For example, what are the help seeking patterns of blacks with "mental health" problems? What percentage of blacks in distress actually use mental health sources? What professional resources are used by blacks with mental health problems as alternatives to the mental health sector? How much is the informal social network relied upon by blacks with mental health problems? What are the different ways blacks in distress actually define that distress? How do these differential definitions influence whether help is sought in the health sector, the mental health sector or at all?

Most of our knowledge regarding the black help seeking process has been gained from racial comparison studies. While these studies have provided some sense of the gross differences between blacks and whites, they have also obscured what may be important dimensions of black problem definition and help seeking behavior. The clarification of how racial minorities define mental health problems, seek help for those problems and evaluate that help can only add to our understanding of help seeking in general. Progress in this understanding can only be made by exploring the heterogeneity of help seeking behavior within the black population. For more practical reasons, health planning policies which are based on data which assume that all blacks, regardless of their health status, economic status, age or gender, exhibit the same patterns of illness behavior are too simplistic to have a meaningful impact upon the groups toward which they are targeted.

The purpose of the present study is to investigate the impact of personal problem definition and problem severity on the use of professional help in a national sample of black Americans. In addition to clarifying our understanding of the black help seeking process, the analyses may also be useful in clarifying the meaning of official mental 
health utilization statistics by pointing out where and how such data falls short of adequately describing the factors that influence when blacks seek help and when they do not.

\section{METHOD}

\section{Sample}

The analyses were conducted on a national cross-section sample of the adult (18 years old and older) black population living in the continental United States. The sample was drawn according to a multi-stage, area probability procedure designed to insure that every black household had the same probability of selection. A total of 76 primary areas were selected for interviewing based on the 1970 census distribution of the black population. These sites were stratified according to racial composition and smaller geographical areas ("clusters") were randomly chosen. Next, professionally trained interviewers listed the habitable households in each cluster. Since correct identification of eligible dwelling units was critical, special screening procedures were developed for finding black households in low density black areas. Finally, within each selected black-occupied household a single person was randomly chosen from the list of eligible adults to be interviewed. The sampling and interviewing procedure resulted in 2,107 completed interviews conducted in 1979 and 1980, representing a response rate of $67 \%$.

\section{Instrument}

The section of the questionnaire designed to study mental health-related issues was organized around the concept of a "stressful episode." Respondents were asked to report a personal problem they had experienced in their lives that had caused them a significant amount of distress. If a person had experienced such a personal problem, they were asked to describe the problem in detail. They were also asked a series of questions designed to elicit information on how they adapted to this stressful event. The present analysis focuses on the 1,322 respondents who reported experiencing a personal problem. Respondents who did not indicate having a serious personal problem were not asked the series of questions analyzed below.

The specific items used to elicit information about this personal problem were: 1 . "When problems have come up, has there ever been a time when you were about at the point of a nervous breakdown?" 2. (If answered "no" to the first question) "Has there ever been a time when you had a personal problem where you felt so nervous you couldn't do much of anything?" 3. (If answered "no" to 2) "Has there ever been a time when you felt down and depressed, so low that you felt you just couldn't get going?" 4. (If answered "no" to 3) "Have you ever had a personal problem you couldn't handle by yourself?" 5 . (If answered "no" to 4) "Have you ever had what you thought was a serious personal problem that you tried to handle by yourself?"

Problem Severity. The concept of "need" for professional help is viewed as a rough approximation of how much the problem interfered with the person's ability to perform their usual social obligations. It was constructed from the above set of five questions. Those respondents who experienced their problem at the point of a nervous breakdown represent "high" problem severity, while those who experienced their problem at some level of distress below the nervous breakdown point (questions two through five) represent "low" problem severity.

Problem Type. Every respondent who said they had experienced a problem was asked the following question: "Thinking about the last time you felt this way, what was the problem about?" This question was designed to ascertain how the respondent conceptualized the nature of the distress experienced. The answer to this question represents the specific locus to which the respondent attributed the cause of his/her personal 
distress. For analytical purposes, responses to this question were categorized into five problem categories: (1) physical health problems, (2) interpersonal difficulties (marital problems, problems with the opposite sex and interpersonal relationships in general), (3) emotional adjustment problems (references to mood disturbances, self doubt and personal adjustment issues in general), (4) death of a loved one, and, (5) economic difficulties.

Professional Help Utilization. If the respondent had experienced a problem, they were presented with a list of professional helping facilities and asked if they had gone to any of the places listed for help with their personal problem. That list included the following professional help sources: hospital emergency room, social services, mental health center, private mental health therapist (i.e. psychiatrist/psychologist), doctor's office, minister, lawyer, police, school, employment agency. In the present report, the decision to seek professional help is operationally defined by a dichotomous variable, indicating whether or not help was sought from at least one of the above professional helping services. The use of specific professional help sources is explored through the use of a series of dichotomous (yes, no) variables. These variables are: hospital emergency room, doctor, social services, mental health center, psychiatrist/psychologist and minister. The use of lawyer, police, school and employment agency are excluded from this analysis.

Persons who indicated that they had sought professional help were allowed to mention as many places contacted up to a limit of four. As a result, the analysis combines multiple mentions if a particular respondent had indeed contacted more than one professional help source. In coding the data in this manner some respondents who were "multiple users" may appear in the yes category more than once depending on which particular professional help sources they contacted. For example, a respondent who had utilized both a social service agency and a community mental health center would be counted as using help during the analysis on social services use as well as on the use of mental health centers. It was felt that by creating a series of dichotomous variables which take into account multiple mentions a more complete description of help seeking variability could be given than would be possible had one polytomous utilization variable based on the first mention only been used.

\section{RESULTS AND DISCUSSION}

Table 1 shows the univariate distributions for problem severity, problem type and the use of informal and professional help. Almost half $(47.4 \%)$ of the people who experienced a personal problem felt that it took them to the point of a nervous breakdown. The majority $(41.4 \%)$ defined their distress as being caused by an interpersonal difficulty. About 1 in 5 $(21.6 \%)$ were upset because of an economic problem. Sixteen percent were suffering from a physical health problem while $11.9 \%$ mentioned an emotional problem. Nine percent said the death of a loved one caused them to be upset.

Table 1 also shows that $87 \%$ of the respondents with a problem seek help from at least one member of the informal social network, while a little less than half (48.7\%) seek some type of professional assistance. Examination of the specific professional help resources utilized (Table 2) shows that hospital emergency rooms $(21.9 \%)$, physicians $(22.3 \%)$ and ministers $(18.9 \%)$ are the most frequently contacted. Eight percent use social services, $4 \%$ go to mental health centers while $5 \%$ contact a psychiatrist or psychologist. 
Table 1. Problem Severity, Problem Type and Help Use

N

\section{Problem \\ Severity}

Nervous

Breakdown

Beneath

Breakdown

Problem

Type

Physical

Interpersonal

Emotional

Death

Economic

Informal

Help Use

Used Informal Helper

Didn't Use Informal Helper

\section{Professional}

Help Use

Used Professional Help

Didn't Use Professional Help
626

47.4

696

52.6

16.2

496

41.5

142

11.9

106

8.9

258

21.6

1134

87.2

166

12.8

631

48.7

666

51.3

Table 3 shows how problem severity and problem type are related to the use of specific professional help sources. Experiencing a problem at the nervous breakdown level slightly increases the likelihood of professional help use across all resources, although this relationship is significant $(\mathrm{p}<.001)$ for psychiatric/psychologist only. Having a physical health problem significantly increases the likelihood of using professional help in general, emergency ${ }_{s}$ rooms and physicians. Defining distress as due to an economic difficulty increases the likelihood of contacting a social service agency for help. People with emotional problems are more likely to contact a psychiatrist/psychologist or a mental 
Table 2. Use of Specific Professional Help Sources (first mention)

\begin{tabular}{lrrr}
\hline & N & & \\
& & & \\
& & & \\
& 138 & 21.9 & 10.6 \\
Emergency Room & 141 & 22.3 & 10.9 \\
Physician's office & 50 & 7.9 & 3.8 \\
Social Services & 25 & 4.0 & 1.9 \\
Mental Health Center & 33 & 5.2 & 2.5 \\
Psychiatrist/Psychologist & 119 & 18.9 & 9.2 \\
Minister & 125 & 19.9 & 9.1 \\
Other & 666 & & 51.3 \\
Did not seek & & & \\
a & & & \\
Percentages based on the 631 respondents who sought professional help. & & \\
bercentages based on the 1,322 respondents with a problem.
\end{tabular}

health center, although this last relationship is not significant at $p<.05$. Finally, Table 3 reveals that losing an important other significantly increases the likelihood of contacting a minister for help.

The first important point to be made from these results is that very few black respondents who had a serious personal problem sought help within the mental health sector. Only $4 \%$ of the people who sought

Table 3. Bivariate Relationships between Personal Problem Characteristics and The Use of Professional Helpa,b

\begin{tabular}{|c|c|c|c|c|c|c|c|}
\hline & $\begin{array}{r}\text { Decision } \\
\text { to seek }\end{array}$ & $\begin{array}{c}\text { Emergency } \\
\text { Room }\end{array}$ & $\begin{array}{c}\text { Private } \\
\text { Physician }\end{array}$ & $\begin{array}{c}\text { Social } \\
\text { Services }\end{array}$ & $\begin{array}{c}\text { Mental Health } \\
\text { Center }\end{array}$ & $\begin{array}{r}\text { Psychiatrist/ } \\
\text { Psychologist }\end{array}$ & Ministe \\
\hline \multicolumn{8}{|l|}{ Problen } \\
\hline Severity & & & & & & & \\
\hline Breakdown & 55.1 & 27.3 & 39.9 & 17.0 & 9.4 & $15.0^{*}$ & 32.3 \\
\hline Beneath Breakdown & 42.6 & 21.5 & 31.6 & 11.5 & 3.5 & 5.6 & 29.9 \\
\hline
\end{tabular}

Problem

Type

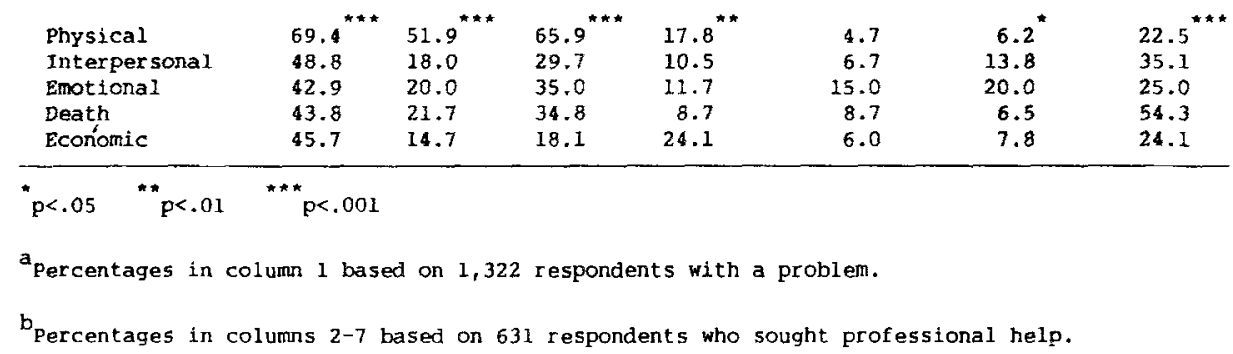


professional help ( $2 \%$ of the people with a problem) went to a mental health center. Another $5 \%$ of the professional help users ( $21 / 2$ percent of the people with a problem) contacted a psychiatrist or psychologist. In short, blacks in distress tend not to seek help from traditional mental health resources for their personal problems. The present study defined psychological distress according to public conceptions as opposed to professional criteria (e.g. DSM-III). Thus it is really not known how many respondents who defined themselves as having an "emotional" problem (or any other type of problem for that matter) or as being at the point of a nervous breakdown would be diagnosed by a professional clinician as suffering from a classifiable psychiatric disorder. Nevertheless, these self-defined labels are important because they represent the primary problem definitions that influence whether or not professional help is sought. It is only after these primary problem definitions take place that secondary problem definitions (diagnoses) can be arrived at according to professional conceptualizations of morbidity.

An important point of this paper was to arrive at some conclusions about what blacks do about personally defined mental health related problems. Given the definitional ambiguities outlined above, it is clear that this issue can be examined from a number of perspectives. For example, during pretesting for this study, blacks revealed that nervous breakdown was the term used most often to describe a severe psychiatric difficulty that was treatable. A person at the point of a nervous breakdown was definitely having a psychological problem, but was not necessarily chronically mentally ill. When the help seeking behavior of those who indicated being at the point of a nervous breakdown is studied, the following statistics are noted. First, a little more than half (55\%) of this group sought professional assistance. In other words, $45 \%$ of the respondents with a problem they defined as a nervous breakdown did not see fit to get any type of professional help for that difficulty. Second, of the $55 \%$ who did seek professional help, $15 \%$ contacted a psychiatrist or psychologist and 9.4\% contacted a mental health center. Thus, approximately $3 / 4(76 \%)$ of the people at the point of a nervous breakdown who sought professional help, did not contact a mental health resource.

Another way to view this issue is to investigate the help seeking responses of those respondents who defined themselves as having an emotional problem. This is an especially important group given the focus of this paper. These are the only respondents who when asked to elaborate on the nature of their personal problem, emphasized disturbances in affect and mood as opposed to stating what specific "bad thing" caused them to become upset. In many ways this group may truly represent those blacks who self defined themselves as having a mental health problem. Among this group, a total of $35 \%$ went to a psychiatrist/ 
psychologist or to a community mental health center. One cannot help but wonder about the other $65 \%$ of the respondents who emphasized mood disturbances but did not seek help from a mental health source. It could be that many of these respondents turned to other, non-mental health sources of help. These data show that the traditional health care sector is frequently used by blacks in psychological trouble. The findings indicate that $40 \%$ of the respondents who felt at the point of a nervous breakdown sought help from a regular physician and $27 \%$ contacted the hospital. Furthermore, $35 \%$ of the people with an emotional problem approached a physician while $20 \%$ contacted the hospital. These percentages equal or exceed the proportion of individuals who contacted a mental health source (either a mental health center or psychiatrist).

It may be that people who use social service agencies are receiving mental health counseling. A more in-depth analysis (Neighbors, 1982) of the respondents who contacted a social service agency revealed that $70 \%$ were helped by a social worker and $10 \%$ saw a physician. It was impossible to tell whether the social workers were specially trained in the mental health area or not. The type of help offered by these social workers was explored, however. In summary, $46 \%$ of the respondents received some kind of specific, active, concrete help, $22 \%$ received socioemotional help, $12 \%$ got some financial assistance while $20 \%$ felt they got no help. It is not completely clear whether social service agencies should be considered "mental health" sources or not. It is interesting to note, however, that only $17 \%$ of the respondents at the nervous breakdown level and only $12 \%$ who labeled their problem as emotional sought help from a social service agency.

The fact that a large number of respondents who had a serious personal problem did not seek any form of professional help implies the existence of a large pocket of unmet need for help in the black community. If the extensive use of the informal social network is taken into account, however, the situation does not appear as bleak. It should be noted that $87 \%$ of the respondents with a problem sought some type of informal help (Table 1). Only $9 \%$ of the respondents with a problem go unaided if the use of informal and formal help is looked at in combination (Neighbors \& Jackson, in press). There was evidence that people with emotional problems were significantly more likely than persons with other types of problems not to seek any outside help at all (Neighbors \& Jackson, in press). Thus, the stigma that may be attached to defining one's distress within a mental health perspective may be impeding the access of blacks to both informal and professional services. This is a potential risk group that perhaps needs to be a target for outreach services of various mental health agencies. 


\section{CONCLUSIONS}

These results raise a number of practical implications. First, it is clear that estimations of the prevalence of various forms of psychiatric morbidity in the black population based on their numbers in mental health facilities will be grossly inaccurate. These data show that the majority of blacks with problems that can be viewed within a mental health framework either seek no professional help at all, or utilize the traditional health sector. This is not atypical. Regier, Goldberg and Taube (1978) report that only $1 / 5$ of the people estimated to have a mental disorder (during any year) utilize the specialty mental health sector; $60 \%$ of this group, however, do seek help within the primary care outpatient/medical sector.

The findings reported here serve as empirical documentation of the tremendous variability of help seeking behavior within the black population. These results also document what many have speculated about for some time; the importance of the Black Church, and especially ministers in counseling blacks who are troubled. Ministers are especially important among respondents who were distressed because of the death of a loved one-54\% of this group sought help from a minister. These findings point out the need for better information on the type of help received by blacks with mental health problems who 1) do not seek professional help, and 2) seek help from non-mental health professionals. For example, future analyses on the type of help offered by ministers to blacks in distress will be extremely important in documenting potential mismatches between type of problem and type of helper. Death problems of a fairly non-serious nature (i.e., low rates of distress) can probably be easily handled by ministers. On the other hand, to the extent that high rates of distress are indicative of the probability of having a more serious psychiatric disorder (and of the need for more professional consultation), one would expect ministers to make referrals to the appropriate help resources. It is not clear that such referrals are made.

The next important question to be answered is why black Americans choose not to contact mental health sources, even with apparently serious and appropriate personal problems. One possible reason is the stigma attached to being known as a "case" in a mental health agency. Blacks may also perceive the type of help offered in mental health agencies as ineffective or may anticipate barriers to the receipt of effective help. If such feelings are prevalent in black communities, then the type of referral advice offered to potential help seekers by members of the informal network may channel people into the traditional health sector as opposed to the mental health sector. This would account for the relatively large proportion of respondents in the current study who reported seeking help from physicians and hospitals. 
This paper investigated help seeking behavior using a black sample. As a result, the questions raised in the Introduction were in specific reference to black illness behavior; but such questions are important and relevant for all racial/ethnic groups. It is certainly fair to ask whether the findings reported here (for black Americans) would be similar to (or different from) results obtained on other groups had they been included in this study. One of the major motivations behind the Program for Research on Black Americans is the assumption that blacks and whites are members of different cultures and that research on these groups should be sensitive to such cultural differences (Jackson, Tucker \& Bowman, 1982). Within this orientation it is not unreasonable to assume that these two groups would exhibit different responses to stressful situations.

This is ultimately an empirical question. Unfortunately, no other large-scale surveys have employed the methodological approach used in the National Survey of Black Americans (NSBA). The closest is the approach used by Veroff, Kulka and Duvan (1981) in their replication of the classic, Americans View Their Mental Health (Gurin, Veroff \& Feld, 1960). Most of the professional help seeking data reported by Veroff et al. (1981) is in reference to a hypothetical personal problem described as being "very unhappy or nervous or irritable all the time, like when a husband and wife are not getting along, a problem with a child or a job" (p. 78). Veroff et al. (1981) felt this description implied that the problem was related to the person's own malfunctioning. The authors report a very high utilization rate of the mental health sector for such problems. More relevant for the present paper though, is the data reported by Veroff et al. (1981) on formal help seeking for personal crises. Crises are stressful things that happen to a person; they do not necessarily imply any personality defect. This is precisely the perspective adopted by the NSBA (Neighbors et al., 1983).

Veroff et al. (1981) reported that $21 \%$ of those who sought formal help for crises ( $8 \%$ of the total sample) consulted a mental health source. Fifty-three percent of those with crises labeled as emotional and $44 \%$ of those with interpersonal crises contacted a mental health source. Finally, over $25 \%$ of those with material problems (economic, work, school, legal) sought mental health consultation. Unfortunately, Veroff et al. (1981) reported none of these data by race.

While the approach used in the Veroff et al. study is similar to the one employed here, it is not exactly the same. Thus, one must be careful in comparing the utilization rates across these two studies. It does seem to be the case though, that blacks in our sample do not consult mental health resources for personal crises in the same numbers as whites did in the Veroff et al. (1981) study. The apparent underutilization of mental health services by blacks (and other ethnic minorities) in comparison to whites has been widely discussed (Snowden, 1982). Comparisons made 
here seem to support that notion, but more definitive statements must wait until the appropriate comparative analyses are undertaken. The NSBA has no whites in its sample but the Veroff et al. (1981) data does have a small number of black respondents. Fortunately analyses of these data are continuing and reports on race and help seeking should be forthcoming (Broman, 1984). Useful information on race and help seeking for mental health problems should also be available soon from the National Institute for Mental Health's Epidemiologic Catchment Area Program. Until such work is completed and until the present methodological approach is replicated on ethnically diverse samples, we cannot state with any great degree of certainty the extent to which these findings can be generalized to other racial/ethnic groups.

\section{REFERENCES}

Broman, C. Race differences in professional help seeking. Unpublished manuscript, University of Michigan 1984.

Cannon, M. \& Locke, B. Being black is detrimental to one's mental health: Myth or reality: Phylon, 1977, 38, 408-428.

Fischer, J. Negroes and whites and rates of mental illness: Reconsideration of a myth. Psychiatry, $1969,32,428-446$.

Fried, M. Social differences in mental health. In J. Kosa \& I. Zola (Eds.), Poverty and health (2nd ed.). Cambridge, MA: Harvard University Press, 1975.

Frumkin, R. Race and major mental disorders. Journal of Negro Education; 1954, 23, 97-98.

Jackson, J., Tucker, M.B., Bowman, P.J. Conceptual and methodological problems in survey research on black Americans. In W. Liu (Ed.), Methodological problems in minority research. Pacific/Asian American Mental Health Research Center, 1982.

Gurin, G., Veroff, J., Feld, S. Americans view their mental health. New York: Basic Books, Inc., 1960.

Kramer, M:, Rosen, B., Willis, E. Definitions and distributions of mental disorders in a racist society. In C. Willie, B. Kramer, B. Brown (Eds.), Racism and mental health. Pittsburgh: University of Pittsburgh Press, 1973.

Malzberg, B. Mental disease among Negroes in New York state, 1934-41. Mental Hygiene, 1953, $37,450-476$.

Mechanic, D. Symptoms, illness behavior, and help seeking. New York: Prodist, 1983.

Neighbors, H., Jackson, J., Bowman, P. \& Gurin, G. Stress, coping and black mental health: Preliminary findings from a national study. Prevention in Human Services, 1983, 2, 5-29.

Neighbors, H. \& Jackson, J. The use of informal and formal help: Four patterns of illness behavior in the black community. American Journal of Community Psychology. In press.

Neighbors, H. Socioeconomic status and the use of professional help: A national study of black illness behavior. Unpublished doctoral dissertation, University of Michigan, 1982.

Regier, D., Goldberg, I., Taube, C. The de facto U.S. mental health services system: A public health perspective. Archives of General Psychiatry, 1978, 35, 685-693.

Snowden, L. Reaching the underserved: Mental health needs of neglected populations. Beverly Hills: Sage Publications, 1982.

Thomas, A. \& Sillen, S. The pitfalls of epidemiology. In A. Thomas \& S. Sillen (Eds.), Racism and Psychiatry. New York: Brunner/Mazel, 1972.

Veroff, J., Kulka, R., Douvan, E. Mental health in America: Patterns of help seeking from 1957 to 1976. New York: Basic Books, 1981. 